\title{
TÉCNICAS DE SEGMENTAÇÃO DE IMAGENS E CLASSIFICAÇÃO POR REGIÃO: mapeamento da cobertura vegetal e uso do solo, Mucugê-BA
}

\author{
Prof ${ }^{a}$. Msc. Elane Fiúza Borges \\ Universidade Federal da Bahia - Instituto de Ciências Ambientais e Desenvolvimento Sustentável \\ Prof. José Seabra, S/N - Centro, CEP:47805-100 - Barreiras-/BA - Brasil \\ Tel: (55 77) 3614.3500 - elaneborges@gmail.com \\ Prof. Dr. Ardemírio de Barros Silva \\ abarros@uefs.br
}

\begin{abstract}
RESUMO
A classificação de imagens de satélites tem como objetivo distinguir e identificar as características dos diferentes alvos imageados. O objetivo deste trabalho foi o de elaborar o mapa de cobertura vegetal e uso do solo a partir da utilização das técnicas de segmentação de imagens e classificação por região, do município de Mucugê, localizado na Chapada Diamantina - Ba. Para o desenvolvimento da pesquisa vários testes de segmentação foram realizados, sendo escolhido para classificação a imagem Aster segmentada, cujos parâmetros de similaridade e área foram 50 e 36, respectivamente. O algoritmo utilizado foi o Bhattacharya, com limiar de aceitação de 99,9\%. Na etapa de Classificação foram identificadas as seguintes classes: Áreas antropizadas, constituídas por agricultura de pequena escala, pastagens e construções, equivalente a 16,2\% da área de estudo; Agricultura irrigada por pivô-central, corresponde a 4,2\%; Savana GramíneoLenhosa e Campo Rupestre, equivalente a 19,1\%; Savana Arborizada corresponde a 35,5 \% e finalmente a Vegetação Densa, correspondente a $25 \%$ da área total. Na validação utilizou-se o índice Kappa que apresentou resultado 0,76, demonstrando substancial correspondência.
\end{abstract}

Palavras-chave: Segmentação, classificação por região, Chapada Diamantina.

\begin{abstract}
Satellite imagery classification aims to distinguish and to identify the characteristics of different target located images. The objective of this study was to develop a vegetation cover and soil use map using Digital Image Processing (segmentation and region classification) using Aster images. The study area is located in the municipal district of Mucugê (Chapada Diamantina, Bahia State). To accomplish the objectives, several tests were carried out and the chosen similarity were 50 and 36 . The Bhattacharya algorithm was used, with the acceptance threshold of $99.9 \%$. After the classification processes were finished it was possible to identify the following classes: anthropic areas, consisting of small-scale agriculture, pastures and buildings, equivalent to $16.2 \%$ of the study area, agriculture irrigated by centerpivot, is $4.2 \%$; Savana grassy-woody and rocky savana, equivalent to $19.1 \%$; Savanna trees are $35.5 \%$ and finally the dense vegetation, corresponding to $25 \%$ of the total area. For validation, the Kappa index was used and the results showed that 0.76 , showing significant correlation.
\end{abstract}

Key words: Segmentation, region classification, Chapada Diamantina.

\section{RESUMEN}

La clasificación de imágenes de satélite tiene como objetivo distinguir e identificar las características de los diferentes puntos fotografados. El objetivo de este estudio fue diseñar el mapa de cobertura vegetal y uso del suelo a partir de la utilización de técnicas de segmentación de imágenes y la clasificación por región del municipio de Mucugê, ubicado en la Chapada Diamantina - BA. Para el desarrollo de investigaciones dirigidas a las distintas pruebas que fueron realizadas, siendo elegidos para clasificación el imagen segmentada Aster, cuyos parámetros de similitud y la zona fueron de 50 y 36, respectivamente. El algoritmo utilizado fue el Bhattacharya, con el umbral de aceptación de 99,9\%. En la etapa de clasificación se identificaron las siguientes clases: áreas alteradas, constituídas por la agricultura de pequeña escala, los pastos y construcciones, lo que equivale al 16,2\% del área de estudio; la agricultura de irrigación por pivote central corresponde a 4,2\%; sabana gramíneo leñoso y campos de roca, lo que equivale al 19,1\%; sabana arbolada corresponde a $35,5 \%$ y finalmente la vegetación densa que corresponde a $25 \%$ del total. Para la validación se utilizó el índice de Kappa que presentó resultado 0,76, demonstrando sustancial correspondencia.

Palabras-clave: Segmentación, clasificación por regiones, Chapada Diamantina.

\section{INTRODUÇÃO}

O conjunto de elementos, tais como vegetação, relevo, geologia e solo, gera as unidades de paisagem que podem ser identificadas em uma imagem de satélite, por meio das características espectrais, de forma, de textura, de cor e de tonalidade, que podem formar áreas homogêneas. A 
existência de certos padrões de unidades de paisagem, tais como áreas irrigadas através de pivôcentral, são particularmente bem marcadas. Tais alvos são identificados quando os valores de similaridade e de área atribuídos para os cálculos da segmentação expressam a realidade de campo.

Espindola (2005) explicou que o algoritmo de segmentação é baseado na tradicional técnica de crescimento de regiões, consistindo em um processo de interatividade no qual regiões são agrupadas a partir de pixels individuais. Tal implementação propõe um agrupamento de regiões baseado no conceito de região vizinha mais similar, o que significa dizer que a cada iteração o par mais semelhante de regiões espacialmente adjacentes são fundidos.

A classificação de imagens de satélites tem como objetivo distinguir e identificar as características dos diferentes alvos em uma imagem de satélite, a exemplo das classes de vegetação, uso do solo, tipos de rochas, entre outros. Contudo, a técnica de classificação de imagens apresenta limitações no que se refere a simplificação das informações contidas em uma imagem, pois na verdade existe grande complexidade em uma cena de satélite (CRÓSTA, 1999).

O objetivo deste trabalho consistiu em elaborar o mapa de cobertura vegetal e uso do solo, a partir da utilização das técnicas de segmentação de imagens e classificação por região, para o município de Mucugê. A utilização de tais métodos é relevante porque permite distinguir e identificar as características dos diferentes alvos em uma imagem de satélite, a exemplo das classes de vegetação e uso do solo ou áreas heterogêneas, onde se tem uma diversidade de informações.

A área de estudo é o município de Mucugê, localizado na Chapada Diamantina, no estado da Bahia, como se observa na Figura 1.

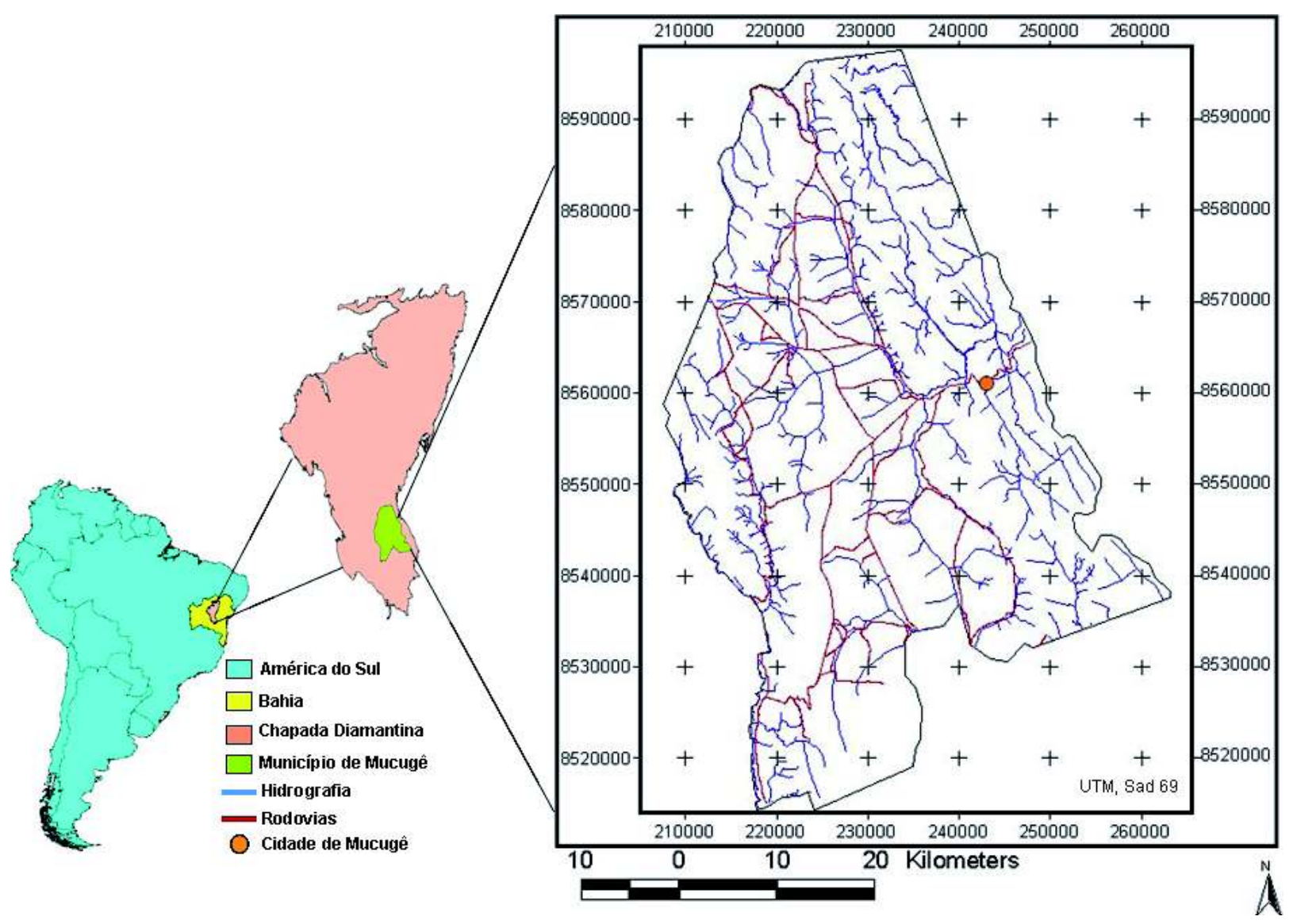

Figura1: Localização da área de estudo

\section{Segmentação}

Segundo Nascimento et al, (1998), a técnica de crescimento de regiões é um processo interativo onde as regiões são unidas através de pixels isolados até que todos os pixels sejam processados, pois a segmentação por região é processada com base nas propriedades dos níveis de cinza, baseando-se 
em duas características intrínsecas: descontinuidade, marcada pelo tamanho da área, e similaridade. Para o desenvolvimento da segmentação fez-se necessário determinar os valores de similaridade espectral e o tamanho da área, como afirmaram Nascimento et al (1998):

A execução do processo de segmentação de imagens exige a definição dos limiares de similaridade e de área, os quais definem a similaridade espectral entre duas regiões e o tamanho da região, respectivamente. O limiar de similaridade é o valor da distância Euclidiana mínima entre as médias das regiões consideradas. E o limiar de área é o valor da área mínima, dado em número de pixel, para que uma região seja individualizada. (NASCIMENTO et al 1998, p.983).

Espindola (2005), concordando com Nascimento et al (1998) afirma que:

No logaritmo de segmentação por região são definidos dois limiares, o primeiro é o de similaridade, abaixo do qual duas regiões são consideradas similares e o segundo é o de área, valor de área mínima para que uma região seja individualizada. O limiar de similaridade é definido com base na distância Euclidiana dada pela diferença entre os vetores de médias de duas regiões vizinhas. (ESPINDOLA, 2005, p.18)

Não existe valor único para a definição dos limiares de similaridade e área, pois estes dependem das características dos alvos que compõem a imagem estudada. Desta forma, os valores mais indicados para se atribuir à segmentação de imagens dependem principalmente dos padrões espaciais existentes na imagem, da diversidade de alvos e da riqueza de detalhes (escala), que deverá apresentar o mapa resultante da segmentação. Não existe, portanto uma padronização de valores destas variáveis para a obtenção de bons resultados.

Para Espindola (2005), quanto à avaliação da segmentação pode-se citar o método qualitativo, que é baseado na inspeção visual dos resultados e que visa a análise de parâmetros como a forma, as dimensões e as bordas das regiões. Este método está atrelado aos objetivos da segmentação da imagem. Um outro método seria o quantitativo, que se divide em analítico e empírico, cujo objetivo, como a própria denominação sugere é o de quantificar os resultados da segmentação. Os métodos analíticos destinam-se à avaliação direta dos algoritmos por meio da análise de seus princípios, suposições e propriedades, sendo que a aplicação deste método de avaliação é independente do objetivo da segmentação.

Quanto à dimensão espacial dos polígonos originados pela segmentação, Gonzalez e Woods (2000), afirmam que o nível até o qual determinada imagem deve ser subdividida depende do problema a ser resolvido. Interpretando a afirmativa dos autores pode-se inferir que os valores de similaridade e área, que definem o grau de detalhamento da segmentação de determinada imagem, estão relacionados aos objetivos propostos pela investigação.

\section{CLASSIFICAÇÃO SUPERVISIONADA POR REGIÃO}

A classificação de imagens de satélites tem como objetivo distinguir e identificar as características dos diferentes alvos em uma imagem de satélite, a exemplo das classes de vegetação, usos do solo, tipos de rochas, entre outros. Contudo, a técnica de classificação de imagens apresenta limitações no que se refere a simplificação das informações contidas em uma imagem, pois na verdade existe grande complexidade em uma cena de satélite (CRÓSTA, 1999).

A classificação supervisionada por região leva em consideração o conhecimento do operador, por meio das amostras de treinamento e a atribuição dada a cada uma delas. O classificador por região exige a definição do limiar de aceitação, definido por Nascimento et al.(1998), como:

(...) limiar de aceitação (distância máxima de Mahalanobis a qual as regiões podem estar afastadas do centro das classes) para a separação ou agrupamento de classes. De modo mais simples, o limiar de 
aceitação pode ser entendido como um hiperelipsóide no espaço de atributos, de tal forma que todas as regiões, cujas médias estiverem dentro do mesmo, são consideradas como pertencentes a uma determinada classe.

\section{MATERIAIS E MÉTODO}

Foram utilizadas para o desenvolvimento desta pesquisa as imagens de satélites do Sensor ETM+/Landsat-7 e imagens do Sensor ASTER; Softwares de processamento digital de imagens e de Sistema de integração de informações geográficas, tais como o Spring, Envi, Idrisi e Arcview. $\mathrm{O}$ metadado das imagens pode ser visualizado no quadro abaixo:

Quadro1: Metadado das Imagens de Satélites

\begin{tabular}{|l|c|c|c|c|}
\hline \multicolumn{1}{|c|}{ SENSOR } & $\begin{array}{c}\text { Resolução } \\
\text { Espacial }\end{array}$ & $\begin{array}{c}\text { Resolução } \\
\text { Radiométrica }\end{array}$ & Data & $\begin{array}{c}\text { Composição } \\
\text { colorida }\end{array}$ \\
\hline Landsat & $30 \mathrm{~m}$ & 8 bits & $28 / 10 / 2001$ & 4R5G7B \\
\hline ASTER & $15 \mathrm{~m}$ & 8 bits & $28 / 10 / 2001$ & 3R2G1B \\
\hline
\end{tabular}

Para o desenvolvimento desta pesquisa utilizou-se a técnica de segmentação de imagem por região com o emprego do algoritmo Bhattacharya. A aplicação desta técnica exige que se definam preliminarmente dois parâmetros, limiar e área.

A especificação do limiar de similaridade é uma etapa importante do processo, pois ele determina a densidade da segmentação: se for muito baixo (pequeno intervalo de reflectância), o processo agregará poucos pixels às regiões e se for muito alto (grande intervalo de reflectância), pixels representativos de muitas regiões serão incorretamente agrupados (ALMEIDA-FILHO; CARVALHO, 2007). Desta forma, foram realizados vários testes de segmentação para imagens Landsat, com diferentes atribuições de área e similaridade. Na primeira segmentação, foram atribuídos os valores de similaridade e área 12 e 16, respectivamente.

Desta forma, procedeu-se segmentação, na qual os valores especificados foram relativamente mais elevados, sendo 15 para similaridade e 25 para área. Na terceira segmentação, a similaridade foi de 50 e o da área foi de 36. Por fim, para a quarta segmentação, foram atribuídos valores relativamente muito elevados, sendo similaridade 64 e área 49, isto porque ao especificar os limiares, o usuário condiciona certo controle ao tamanho mínimo das áreas a serem formadas e a diferença mínima entre os níveis de cinza para a definição de uma borda entre as áreas (ALVES, 1996).

O desenvolvimento dos procedimentos metodológicos, tais como segmentação, identificação das classes, classificação, definição das nomenclaturas para a geração do mapa de uso do solo e cobertura vegetal, pode ser sintetizado no fluxograma apresentado na Figura 2.

Para processar a classificação por região, foi selecionada a quarta segmentação da imagem Landsat com similaridade 64 e área 49, utilizando o algoritmo Bhattacharya, com limiar de aceitação de $99,9 \%$. Os valores de áreas para todos os testes de segmentação realizados, tanto para a imagem Landsat quanto para a imagem Aster, foram quadrados perfeitos $(42=16,52=25,62=36$, $72=49$ ), objetivando o melhor delineamento das regiões na imagem, originadas pelos polígonos da segmentação.

Para a classificação da segmentação da imagem Landsat, foram selecionadas oito classes sendo elas: rocha exposta, vegetação densa, cerrado, agricultura irrigada, nuvem, sombra de nuvem, mata ciliar e agricultura de pequeno porte. $\mathrm{O}$ número de classes definido está atrelado às informações geradas pelos trabalhos de campo e fotointerpretação das imagens de satélites.

Para as segmentações da imagem Aster, os dois últimos testes realizados com a imagem Landsat foram repetidos. Os parâmetros para a primeira segmentação foram similaridade $=50$ e área $=36 \mathrm{e}$ 
para a segunda, os valores atribuídos de similaridade e área foram 64 e 49, respectivamente.

Ao contrário da imagem Landsat, que utilizou a segmentação para ser classificada com os maiores valores de similaridade e área, para a imagem Aster, classificou-se o vetor de segmentação com valores menores (similaridade 50 e área 36).

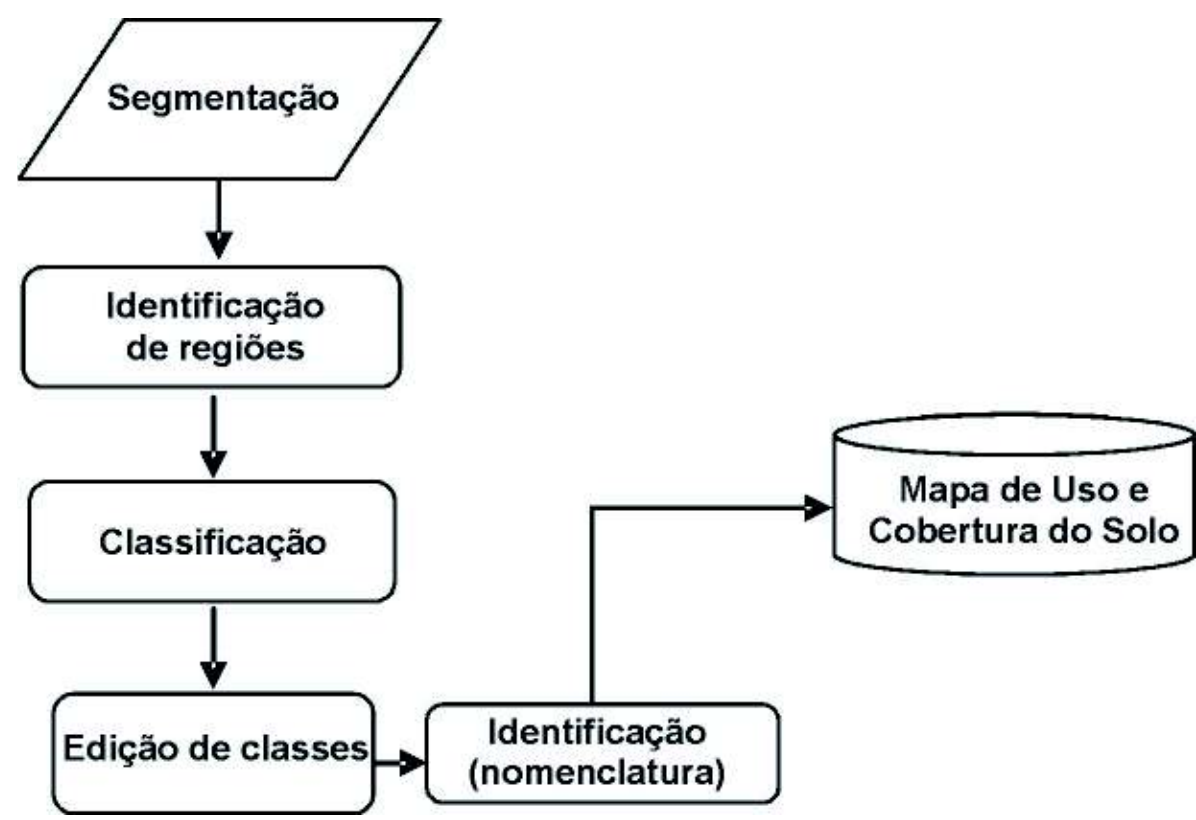

Figura 2: Fluxograma que sintetiza as etapas para a elaboração do mapa de uso do solo e cobertura vegetal

A partir dos testes realizados, o vetor de segmentação selecionado para a classificação, visando à elaboração do mapa de uso do solo e cobertura vegetal, foi o da imagem Aster cujos procedimentos e parâmetros são apresentados de forma sintetizada pelo fluxograma que segue, (Figura 3).

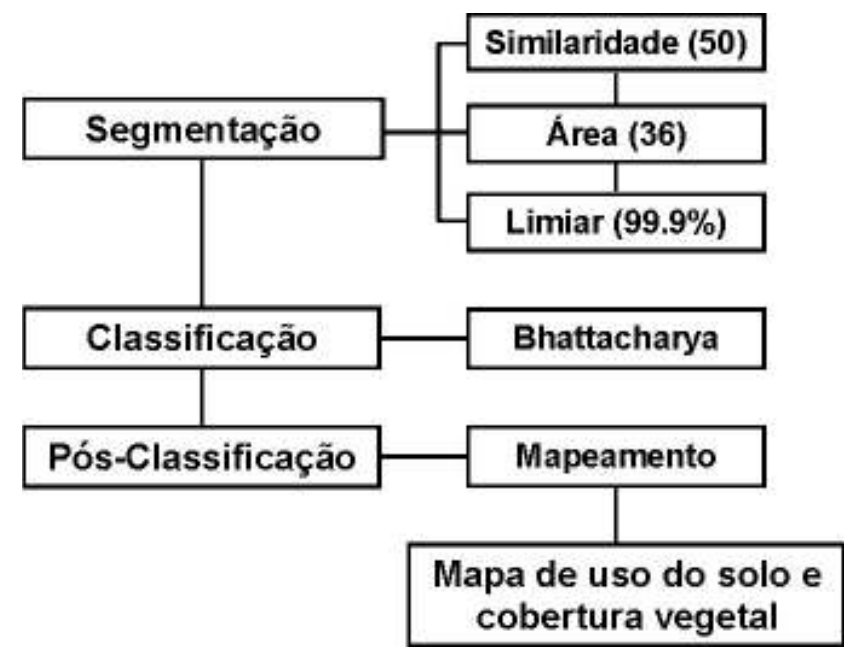

Figura 3: Procedimentos metodológicos para a segmentação da imagem Aster

O mapeamento do uso do solo e da cobertura vegetal contemplou apenas, com algumas adaptações, o primeiro nível de classificação proposto pelo manual técnico de uso da terra elaborado pelo IBGE (2006).

Para a classificação da imagem Aster não foram consideradas as classes de nuvem e sombra de nuvem, pois o objetivo da classificação foi o de produzir o mapa de uso do solo e cobertura vegetal, 
portanto as classes anteriormente citadas não auxiliariam em tal produção. Para identificar os alvos sob nuvens e sombra de nuvens utilizou-se imagens de satélite da mesma data, porém produzidas em horários diferentes, o que permitiu a inserção destes nas devidas classes. Nesta etapa, a supervisão da classificação foi extremamente necessária.

Para a classificação da imagem Aster, adaptou-se a nomenclatura, tendo como suporte o sistema de classificação do uso do solo e cobertura vegetal do IBGE (2006), que compreende as áreas antropizadas, tipos de vegetação e os corpos d'água. As classes temáticas identificadas no mapa de uso do solo e cobertura vegetal foram: Áreas antropizadas: agricultura de pequena escala, pastagens e construções; Agricultura irrigada por pivô central; Savana Gramíneo-Lenhosa e Campo Rupestre; Savana Arborizada; Vegetação Densa: Floresta Estacional, Savana Florestada, Savana Estépica Arborizada e Florestada, e Vegetação com Influência Fluvial; e Corpos D'água (lago artificial da Barragem do Apertado).

\section{RESULTADOS E DISCUSSÕES}

\section{Segmentação}

Foi realizada uma avaliação qualitativa dos resultados da segmentação, com base na fotointerpretação da imagem de satélite, sobrepondo o arquivo vetorial segmentado à imagem. Este procedimento foi adotado porque a análise visual constitui-se em um tipo de validação qualitativa dos vetores de segmentação. Considerou-se para a imagem Landsat a segmentação com valores de similaridade 64 e área de 49. O mesmo procedimento aplicou-se para a imagem Aster, porém para esta selecionou a segmentação cujos valores de similaridade e área foram de 50 e 36, respectivamente. Observando as Figuras 4-a e 4-b, têm-se um recorte da imagem de satélite Aster e do vetor de segmentação correspondente a mesma área.
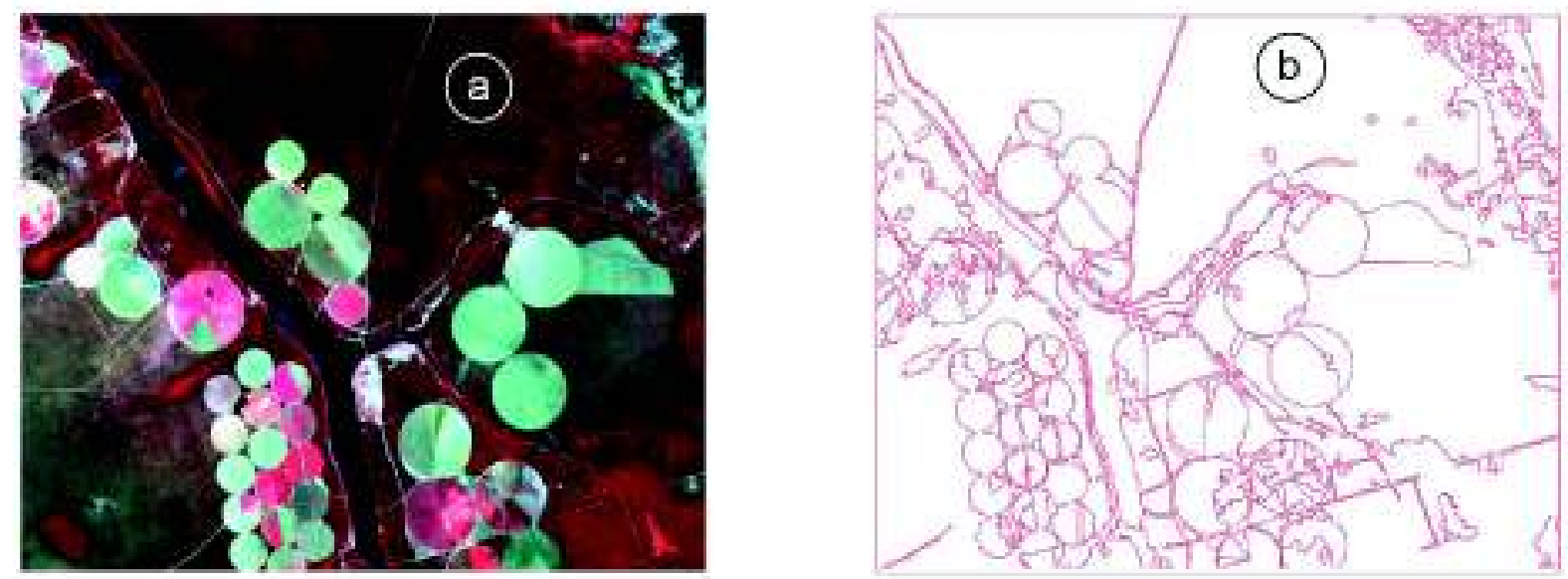

Figura 4 -a: Imagem Aster (R3G2B1); 4-b: Vetor de segmentação (similaridade=50 e área=36)

Para as segmentações com baixos valores de similaridade e área, observou-se nos vetores resultantes um detalhamento das regiões, mais minucioso do que o necessário para atender aos objetivos propostos desta pesquisa. Ao contrário, as segmentações com índices de similaridade e área elevados provocaram generalização de algumas classes, definindo regiões "extensas", em função da amplitude espectral dos alvos.

De acordo com os objetivos, foram analisados e julgados os resultados das segmentações. Os critérios para aceitação ou rejeição dos limiares de similaridade e área foram norteados pela escala de trabalho, na tentativa de evitar o excesso de regiões, o que acarretaria em um número de classes maior do que o desejado ou identificado para a etapa de classificação. Contudo atentou-se para o 
fato de que o esforço empreendido para evitar o excesso de regiões poderia implicar na aglomeração de classes distintas. Além disso, considerou-se a capacidade de separação coerente de níveis de cinza visualmente distintos na imagem.

As segmentações selecionadas para a classificação estavam dentre as que foram processadas

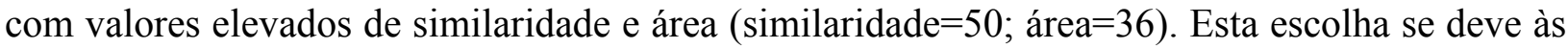
características da área de estudo, por apresentar em alguns pontos grandes áreas homogêneas e baixa complexidade de classes, como acontece na região da Serra do Sincorá, onde se tem um maciço rochoso coberto basicamente por vegetação do tipo Campo Rupestre, bem como na faixa do chamado Geraes de Mucugê, onde predomina a vegetação Savana Arborizada, com exceção das áreas antropizadas pela prática agrícola.

\section{Classificação}

Consistiu na técnica de classificar os alvos pelas características inerentes de reflectância e emitância. O produto resultante da classificação da imagem segmentada, cujo algoritmo utilizado foi o Bhattacharya, foi o mapa de uso do solo e cobertura vegetal (Figura 5).

Com a análise da classificação, pôde-se observar que algumas classes foram generalizadas, pois alvos distintos foram considerados como pertencentes a uma mesma categoria. Isto ocorreu em função de se considerar o limiar de aceitação de 99,9\%, pois quanto maior o limiar, menor é o número de classes espectrais geradas. Por outro lado, reduzir o limiar poderia incorrer no equívoco de se criar um número de classes maior do que o compatível com a escala de trabalho e, portanto, comprometer os resultados que se objetivava alcançar através da segmentação e da classificação por região.

A despeito de selecionar áreas de treinamento para realizar a classificação, alguns polígonos (regiões) que deveriam pertencer a uma determinada categoria foram inclusos automaticamente em outra. Nestas condições, a classificação ocorreu de forma manual, sendo o polígono selecionado e direcionado para a categoria a qual o mesmo deveria pertencer.

\section{Caracterização das classes de uso do solo e cobertura vegetal}

As classes identificadas na classificação que resultou no mapa de uso do solo e cobertura vegetal são caracterizadas a seguir:

As áreas antropizadas são constituídas por agricultura de pequena escala, pastagens e construções e corresponde a uma área de $395 \mathrm{~km}^{2}$, o que equivale a 16,2\% da área total. Nesta zona, predomina os Neossolos, que, de modo geral, possuem alta concentração de quartzo, com granulometria de seixo e areia grossa, o que permite que haja uma alta capacidade de reflectância nas áreas onde este material é encontrado. Isto explica porque muitos fragmentos de Caatinga foram inclusos nesta classe considerada como áreas antropizadas, quer seja pelas construções ou pela atividade agropecuária de pequeno porte.

Espectralmente, áreas desmatadas com solos revirados e com granulometria grossa tendem a apresentar alto índice de reflectância, muitas vezes em função da exposição das arestas do material da composição que aumenta a capacidade de reflectância.

Como na Caatinga predominam os Neossolos Litólicos e os Neossolos Quartzarênicos, esta pode ser a explicação para a mistura de áreas de Caatinga com áreas antropizadas. A despeito da confusão de classes, é importante ressaltar que algumas áreas são realmente antropizadas, cuja vegetação nativa é a Caatinga, porém, muitos remanescentes desta vegetação encontram-se em estágio de degradação, daí a inclusão da caatinga como áreas antropizadas.

Devido ao processo de antropização na Caatinga, formou-se muitas clareiras, o que também pode interferir na classificação dos alvos, de acordo com a resposta espectral. Esta confusão de classes pode ser intensificada quando o fator natural contribui com a ação antrópica, tornando estas clareiras mais expressivas ou melhor visualizadas, como nas áreas cuja vegetação não é densa e nem de grande porte, a exemplo da Savana Arborizada. 


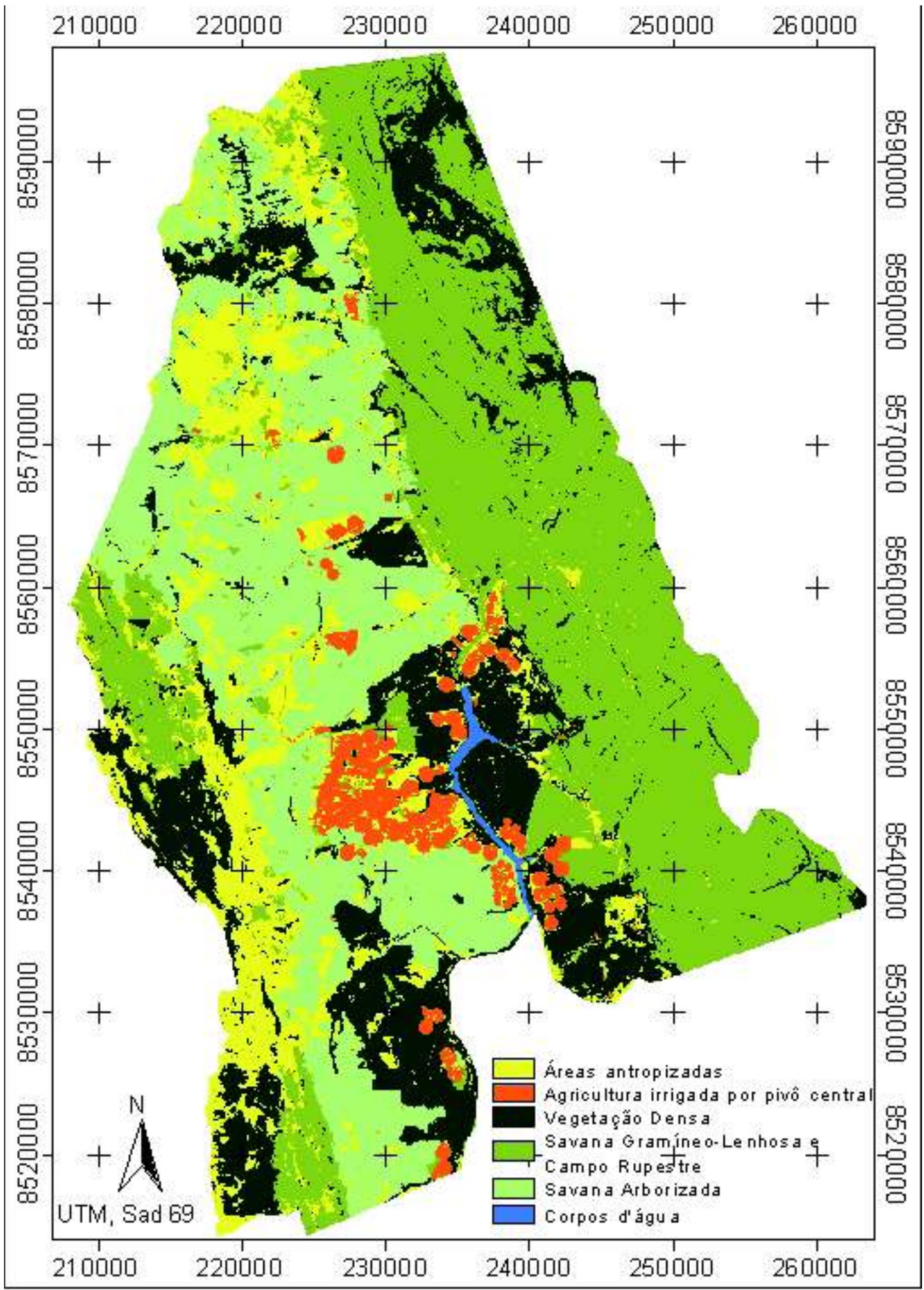

$10 \quad 0 \quad 10$ Kilometers

Figura 5: Mapa de cobertura vegetal e do uso do solo

As áreas antropizadas são também identificadas pela forma geométrica e por tamanhos irregulares, formando arranjos espaciais que são caracterizados por meio da fotointerpretação de imagens como "espinhas de peixe".

Uma outra classe também marcada pela ação antrópica, nesta classificação foi denominada de Agricultura irrigada por pivô-central, compreendendo as áreas onde se pratica a agricultura moderna, com uso de irrigação por pivô-central. Em termos quantitativos, corresponde a 4,2\% da área de estudo, ou seja, aproximadamente $100 \mathrm{Km}^{2}$. 
O padrão mais relevante desta classe é a sua forma circular que apresenta, devido ao sistema de irrigação por pivô-central. Para esta classe, foram identificadas as áreas essencialmente cultivadas e irrigadas por pivô-central, não sendo considerado, por exemplo, o entorno dos pivôs que, muitas vezes, o uso pode estar associado ao agronegócio e inclusive ser um território pertencente à mesma propriedade fundiária. Este procedimento foi adotado na tentativa de evitar que áreas com características espectralmente semelhantes, porém destinadas a outro tipo de uso pudessem ser inclusas. Vale a ressalva de que a delimitação desta classe deu-se em função essencialmente do seu uso. Este procedimento foi corroborado pela classificação por regiões que delimitou com precisão as áreas de pivô, devido principalmente à geometria e a resposta espectral destas áreas. Em cada pivô, cultiva-se apenas uma cultura, o que torna a área bastante homogênea em termos espectrais. Entretanto, nos pivôs cuja cultura é temporária, a colheita pode não ser realizada no mesmo período, isto implicou em uma heterogeneidade espectral destas áreas. Nestes casos, competiu ao intérprete analisar e fazer a inclusão de polígonos, que embora se apresentem espectralmente distintos, poderiam corresponder a mesma classe.

A terceira classe mapeada foi denominada de Savana Gramíneo-Lenhosa e Campo Rupestre, caracterizadas como sendo uma vegetação distinta das demais, representando cerca de 19,1\% da área total ou $477 \mathrm{~km}^{2}$. Esta classe compreende as áreas serranas, estando a maior parte na Serra do Sincorá.

Em função da escala de mapeamento, foi necessário incluir alguns polígonos que poderiam ser caracterizados como outro tipo de vegetação e que não foram especificados nesta classificação. Refere-se às matas de grotões, encaixadas nos fundos de vale, que embora visualizadas na imagem não foram individualizadas na etapa de classificação. O mesmo aconteceu com alguns polígonos de rocha exposta, geralmente no topo da serra, que se apresentavam espectralmente muito semelhante às áreas antropizadas. Estes polígonos foram, na sua maioria, inclusos na macro categoria de áreas serranas, cuja vegetação é predominantemente de Savana Gramíneo-Lenhosa ou de outro tipo de vegetação, que como especificado anteriormente, na ausência de uma nomenclatura mais adequada foi denominada de Campo Rupestre, mesmo não existindo esta classe no sistema de classificação adotado (IBGE, 2002).

Todavia, como foram muitos polígonos pequenos identificados nesta classe como pertencentes às Áreas antropizadas, não foi possível fazer a inserção de todos os polígonos para a classe aqui denominada de Savana Gramíneo-Lenhosa e Campo Rupestre. Por isso, algumas manchas aparecem sobre a Serra do Sincorá classificadas como áreas antropizadas.

A quarta classe identificada nesta classificação corresponde a uma grande área caracterizada pela vegetação de Cerrado que corresponde a Savana Arborizada, que em outro sistema de classificação (Ribeiro e Walter, 1998), corresponde a vegetação de Campo Cerrado. São 882 Km², que correspondem a 35,5\% da área de estudo, encontrados ainda em estado conservação. Esta é uma classe que tende a se reduzir bastante, pois possui as mesmas características físicas da área onde se desenvolve a agricultura irrigada por pivô-central e com o avanço desta ocorrerá, obviamente, uma redução da vegetação de Savana Arborizada.

Como esta classe é considerada uma "unidade de paisagem natural", pode ser identificada pela combinação de elementos físicos responsáveis pela criação de um padrão bastante homogêneo, em função principalmente do relevo. A homogeneidade em termos de textura, tonalidade e forma condicionaram um comportamento espectral específico desta classe, o que contribuiu para o processo de classificação.

Outro tipo de vegetação caracterizado fisionomicamente por um porte maior, nesta classificação foi denominado como a classe de Vegetação Densa, caracterizada pela Floresta Estacional, Savana Estépica Florestada, Savana Estépica Arborizada, Savana Florestada e Vegetação com Influência Fluvial. Esta classe ocupa $625 \mathrm{~km}^{2}$, o equivalente a $25 \%$ da área total. 
Por ser caracterizada como uma vegetação de porte mais expressivo em relação aos demais tipos de vegetação existentes na área de estudo, o processo de classificação obteve desempenho considerável. A composição colorida 3R2G1B da imagem Aster, realçou a vegetação que compõe esta classe, caracterizada como mais densa ou mais sadia, na cor vermelha.

A classe denominada de Corpos D'água diz respeito ao curso hídrico mais expressivo que constitui o lago artificial formado pela Barragem do Apertado no alto curso do Rio Paraguaçu. Esta classe corresponde a uma área de $10 \mathrm{Km}^{2}$, representando cerca de $0,5 \%$ da área total.

É importante ressaltar que os cálculos de áreas, anteriormente apresentados, foram efetuados sobre dados do mapa de uso do solo e cobertura vegetal, o qual foi produzido a partir da imagem de satélite datada do ano de 2001. Portanto determinadas zonas, conforme dinâmica própria ou impulsionada por um fator externo (como a ação antrópica), pode ter sofrido alterações no sentido de expansão ou retração. Isto implicaria em afirmar que os cálculos das áreas das classes estão atrelados a dinâmica espacial das atividades desenvolvidas ou do "comportamento" da cobertura vegetal existente, bem como das interações que ocorrem entre as classes de uso, que caracterizam os polígonos de ação antrópica e as classes de "paisagem natural", nas quais prevalecem os aspectos físicos. A Figura 6 faz uma associação das classes de uso do solo e cobertura vegetal mapeadas aos respectivos alvos identificados na imagem de satélite.

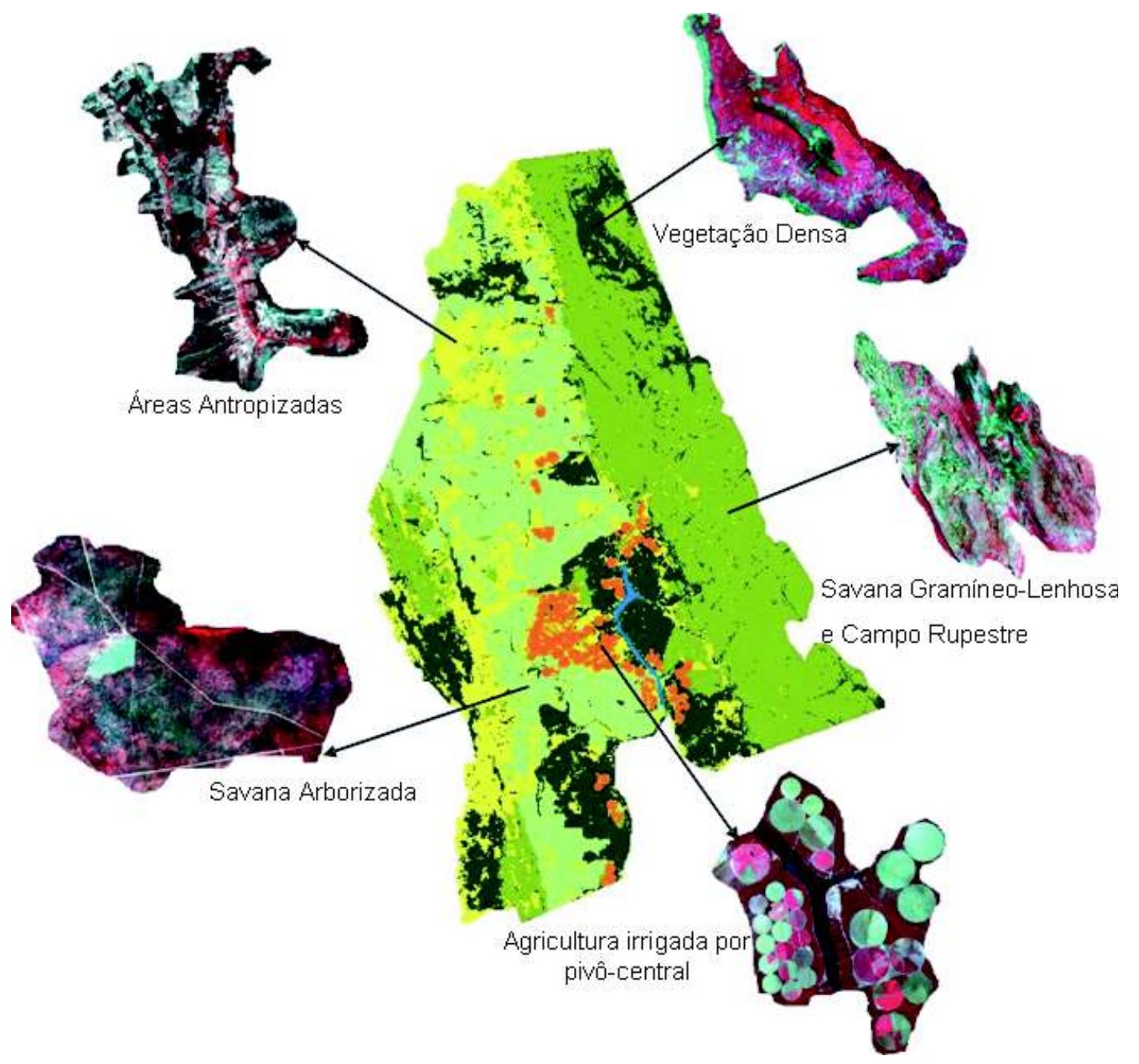

Figura 6: Classes de uso do solo e cobertura vegetal associadas aos alvos identificados na imagem de satélite

\section{Validação do Mapa de Uso do Solo e Cobertura Vegetal}

O procedimento seguinte consistiu na análise comparativa do resultado da classificação às informações produzidas através do trabalho de campo, bem como aquelas geradas a partir da fo- 
tointerpretação das imagens de satélites. Utilizou-se pontos de campo para validar o mapa de uso do solo e cobertura vegetal. O método de validação aplicado foi o índice Kappa.

Considerando uma situação na qual se tem duas hipóteses em teste, expressadas por uma matriz 2x2 na Figura 7, a célula a evidencia a situação em que ambos os mapas estão corretos. A célula $\mathrm{b}$ indica que o mapa real é correto, mas o mapa interpretado está incorreto, portanto ocorre uma incompatibilidade de informações. A célula c, ao contrário, indica que o mapa interpretado está correto e o mapa real incorreto. Finalmente a célula d indica compatibilidade de informações, pois em ambos os mapas a hipótese é falsa.

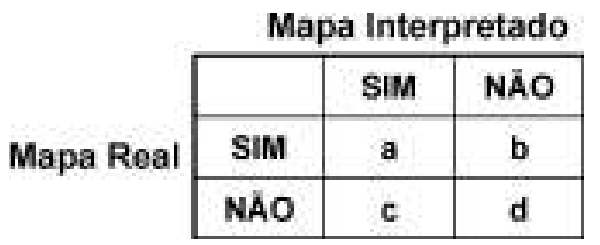

Figura 7: Matriz explicativa do índice kappa

A tabela de correspondência foi aplicada em 50 pontos de campo distribuídos randomicamente. Fez-se necessária a criação de duas matrizes $5 \times 10$, sendo a primeira montada com os dados de campo (dados reais) e a segunda com dados do mapa interpretado (mapa de uso e cobertura vegetal).

A etapa seguinte foi verificar a compatibilidade dos dados da realidade com os dados interpretados. A Figura 8-a, apresenta os dados de campo (realidade) e os dados interpretados. Após montar as matrizes foram realizados os cálculos de compatibilidade e incompatibilidade das informações, como se observa na Figura 8-b.

\section{REALIDADE}

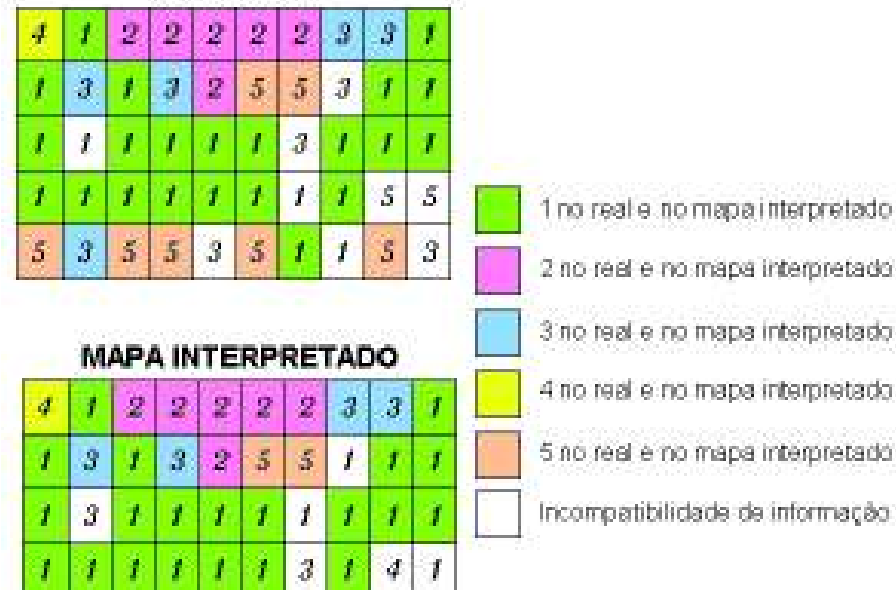

\begin{tabular}{|c|c|c|c|c|c|c|}
\hline & 1 & 2 & 3 & 4 & 5 & \\
\hline 1 & 21 & 0 & 2 & 0 & 1 & 24 \\
\hline 2 & 0 & 6 & 0 & 0 & 0 & 6 \\
\hline 3 & 2 & 0 & 5 & 0 & 2 & 9 \\
\hline 4 & 0 & 0 & 0 & 1 & 0 & 1 \\
\hline \multirow[t]{2}{*}{5} & 1 & 0 & 0 & 0 & 8 & 9 \\
\hline & 24 & 6 & 7 & 1 & 11 & 49 \\
\hline
\end{tabular}

Figura 8-a: Matrizes de correspondência entre os dados reais (pontos de campo) e os dados do mapa interpretado; Figura 8-b: Matriz de contingência apresentando as proporções marginais.

O índice Kappa é calculado pela equação 1:

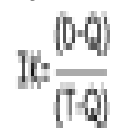

onde, $\mathrm{T}=$ Total de pixel examinados; $\mathrm{D}=$ total de pixel que apresentam compatibilidade representados pela Diagonal principal e $\mathrm{Q}=$ é valor obtido através do cálculo entre os valores das células da diagonal principal e o valor " $\mathrm{D}$ ".

Segundo Silva (2003), quanto mais próximo de 1 for o resultado da aplicação do índice Kappa mais acurado será o dado. Neste caso específico, o valor encontrado foi 0,76 , o que é considerado com substancial correspondência. 


\section{CONSIDERAÇÕES FINAIS}

As técnicas de segmentação e classificação por regiões não dispensam a participação do especialista, embora executadas pelo computador. O operador é quem estabelece os parâmetros e deve instruir, acompanhar e avaliar os resultados, podendo reiniciar o processo sempre que necessário.

Os testes de segmentação realizados foram necessários para se avaliar e o que apresentou melhores resultados. Os valores de limiar e área a serem definidos na segmentação dependem das características da área estudada e dos objetivos da pesquisa.

Os resultados alcançados por meio dos processos de segmentação e classificação das imagens demonstraram-se compatíveis com a realidade de campo, o que pôde ser comprovado com a validação dos resultados por meio índice Kappa.

\section{AGRADECIMENTOS}

À Capes pelo apoio financeiro ao desenvolvimento da pesquisa.

\section{REFERÊNCIA BIBLIOGRÁFICA}

ALMEIDA-FILHO, R.; CARVALHO, C. M. Uso de imagens Landsat-TM para avaliar a extensão da desertificação na região de Gilbués, sul do estado do Piauí. In: Simpósio Brasileiro de Sensoriamento Remoto, 13., 2007. Florianópolis. Anais... São José dos Campos: INPE, 2007, p. 4365-4372.

ALVES, D.S. Mapeamento do Uso da terra em Rôndonia Utilizando Técnicas de Segmentação e Classificação de Imagens TM. Dissertação (Mestrado em Sensoriamento Remoto). INPE - São José dos campos, 1996.

CRÓSTA, Á. P. Processamento Digital de Imagens de Sensoriamento Remoto. Campinas: IG/UNICAMP, 1993. $170 \mathrm{p}$.

ESPINDOLA, G. M. Emprego da estatística espacial na avaliação da Segmentação de imagens de sensoriamento remoto. 30f. Trabalho de curso (Mestrado em sensoriamento Remoto) - INPE, São José dos Campos, 2005.

GONZALEZ, R. C; WOODS, R. E. Processamento de imagens digitais. São Paulo: Blücher, 2000. 509 p. IBGE. Manual Técnico de Vegetação Brasileira. Rio de Janeiro, 2002. 92p.

IBGE. Manual Técnico de Uso da Terra. Rio de Janeiro, 2006. 142p.

NASCIMENTO, P. S. R. et al. Efeito de Pré-Processamento (ajuste) no Desempenho da Segmentação e Classificação De Imagens Landsat-TM.. In: Simpósio Brasileiro de Sensoriamento Remoto, 9,. 1998, Santos. Anais... São José dos Campos: INPE 1998, p. 981-989.

RIBEIRO, J.F. \& WALTER, B.M.T. 1998. Fitofisionomias do Bioma Cerrado. In: E FLORA (S.M. Sano \& S.P. Almeida, eds.). Cerrado: ambiente. Planaltina: EMBRAPA-CPAC, Cap. 3, p. 87-166.

SILVA, A. de B. Sistemas de Informações Geo-referenciadas: conceitos e fundamentos. São Paulo: Unicamp, 2003, 236 p.

Trabalho enviado em setembro de 2009

Trabalho aceito em dezembro de 2009 